\title{
Composition and temperature dependence of cesium-borate glasses by molecular dynamics
}

\author{
Alice Vegiri, Cristos-Platon E. Varsamis, ${ }^{\text {a) }}$ and Efstratios I. Kamitsos \\ Theoretical and Physical Chemistry Institute, National Hellenic Research Foundation, \\ 48 Vassileos Constantinou Avenue, Athens 11635, Greece
}

(Received 24 January 2005; accepted 6 May 2005; published online 14 July 2005)

\begin{abstract}
The structural aspects of $x \mathrm{Cs}_{2} \mathrm{O}-(1-x) \mathrm{B}_{2} \mathrm{O}_{3}$ glasses have been investigated by molecular dynamics as functions of $\mathrm{Cs}_{2} \mathrm{O}$ content $(x=0.2,0.3$, and 0.4$)$ and temperature $(T=300$ and $1250 \mathrm{~K})$. The

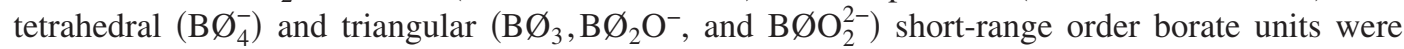
found to be the structure-building entities of the simulated glasses $[\varnothing=$ bridging oxygen $(\mathrm{BO})$ and $\mathrm{O}^{-}=$nonbridging oxygen (NBO) atom]. The increase of $\mathrm{Cs}_{2} \mathrm{O}$ content results in the progressive increase of the NBO-containing triangle population at the expense of the $\mathrm{B}_{4}^{-}$tetrahedral units. The same effect is caused by temperature increase at a fixed $\mathrm{Cs}_{2} \mathrm{O}$ content, and this was associated with the "fragile" characteristics of alkali borate glasses. A comparison of simulated Cs and Li borates showed very similar structures at $x=0.2$, but dissimilar ones when the alkali content exceeds this composition. In particular, for $x>0.2$ Cs borates exhibit a preference for NBO formation relative to Li borates. Differences in the microstructure of sites hosting Cs ions were found, and this permits their classification into bridging ( $b$ type) and nonbridging type (nb type) of sites. $b$-type sites consist exclusively of $\mathrm{BO}$ atoms, while both $\mathrm{BO}$ and $\mathrm{NBO}$ atoms participate in nb-type sites. These differences in Cs-site local bonding characteristics were found to be reflected on the Cs-O(site) vibration frequencies. Also, the computed $\mathrm{Cs}-\mathrm{O}$ vibrational responses for simulated Cs borates were found to compare well with experimental far-infrared spectra. () 2005 American Institute of Physics. [DOI: 10.1063/1.1943414]
\end{abstract}

\section{INTRODUCTION}

Alkali and alkaline-earth borate glasses are characterized by nonmonotonic variations of physical properties with metal oxide content, a phenomenon known as the "boron anomaly" effect. Early studies on borate glasses aimed at elucidating the nature and relative population of the borate units comprising the glass network as a means of providing a structural basis for explaining the boron anomaly effect. ${ }^{1}$ The works of Krogh-Moe by infrared, ${ }^{2}$ Bray and co-workers by $\mathrm{NMR}^{3-5}$ and Konijnendijk and Stevels by Raman spectroscopy ${ }^{6}$ have made pioneering contributions in this field. While glassy $\mathrm{B}_{2} \mathrm{O}_{3}$ is known to result from interconnected $\mathrm{B} \emptyset_{3}$ triangles $(\varnothing$ denotes an oxygen atom bridging two boron centers), a fraction of which is being arranged in planar boroxol rings, ${ }^{2-8}$ addition of metal oxide to boron oxide was found to cause the transformation of neutral $\mathrm{B} \emptyset_{3}$ units into charged $\mathrm{B} \emptyset_{4}^{-}$tetrahedra. For alkali borate glasses, $x M_{2} \mathrm{O}-(1-x) \mathrm{B}_{2} \mathrm{O}_{3}(M=$ alkali $)$, the early studies showed that for $x<0.30$ the fraction of $\mathrm{B} \emptyset_{4}^{-}$units $N_{4}$, follows the law $N_{4}=x /(1-x)$; i.e., each added oxygen atom converts two $\mathrm{B} \emptyset_{3}$ units into two $\mathrm{B} \emptyset_{4}^{-}$tetrahedra, but $N_{4}$ was found to be independent of the nature of alkali metal ion. ${ }^{3-5}$ For alkali modifier contents above ca. $x=0.30$ the network modification involves mainly the formation of nonbridging oxygen atoms (NBO) on borate triangular units, with the number of NBOs

\footnotetext{
a) Author to whom correspondence should be addressed. Fax: +30-2107273-794. Electronic mail: cvars@eie.gr
}

increasing progressively as $x$ changes towards $x=0.75$. These units are the metaborate triangles $\mathrm{B}_{2} \mathrm{O}^{-}$, pyroborate dimers $\mathrm{B}_{2} \varnothing \mathrm{O}_{4}^{4-}$, and orthoborate monomers $\mathrm{BO}_{3}^{3-}$.

In addition to the strong influence of the metal oxide content, studies of physical properties of borate glasses have shown a clear dependence on the type of alkali modifier as well. This is demonstrated by viscosity, ${ }^{9}$ absorption edge, ${ }^{10}$ optical basicity, ${ }^{11,12}$ glass transition temperature, and thermal-expansion coefficient ${ }^{13,14}$ data of alkali borate glasses. It is possible that this dependence on the type of $M_{2} \mathrm{O}$ oxide originates from structural variations, although less pronounced than those induced by the increasing $\mathrm{M}_{2} \mathrm{O}$ modifier content. For example, the viscosity-composition isotherms have been discussed in terms of the field strength of the alkali metal ion, and it has been suggested that for a given $\mathrm{M}_{2} \mathrm{O}$ content the concentration of NBOs increases from $\mathrm{Li}$ to $\mathrm{Cs} .{ }^{9}$ This trend is consistent with the alkali dependence of other physical properties, ${ }^{10-14}$ including sound velocities and elastic constants which decrease systematically as the alkali changes from $\mathrm{Li}$ to $\mathrm{Cs} .{ }^{15}$

Such a disagreement for the role of metal ions, resulted from parallel studies of the structure and properties of alkali borate glasses, appeared to be resolved in more recent NMR investigations of Zhong and Bray ${ }^{16}$ and Bray. ${ }^{17}$ By employing wide-line ${ }^{11} \mathrm{~B}$ NMR with more sensitive instrumentation and signal-averaging techniques, they were able to demonstrate that $N_{4}$ follows the theoretical curve $x / 1-x$ for alkali contents lower than ca. $x=0.15$, but for glasses with larger alkali contents $N_{4}$ is a strong function of the alkali ion. In 
particular, they found the $N_{4}$ fraction to decrease as the size of the alkali metal ion increases. ${ }^{16,17}$ This result reflects a competition between the two transformation processes in the composition range $x \geqslant 0.15$, i.e., the parallel formation of $\mathrm{B} \varnothing_{4}^{-}$tetrahedra and NBO-containing borate triangles. A similar dependence of the borate structure on alkali metal type was revealed by $\operatorname{Raman}^{18}$ and infrared ${ }^{19,20}$ spectroscopy, as well as by molecular-dynamics simulations of borate glasses. ${ }^{21,22}$ Youngman and Zwanziger ${ }^{23}$ concluded from their ${ }^{11} \mathrm{~B}$ dynamic-angle spinning (DAS) NMR study of $\mathrm{Rb}$ borate glasses that the $N_{4}$ values were consistent with those determined in the NMR study of Zhong and Bray ${ }^{16}$ and Bray. ${ }^{17}$ Also, a recent neutron-scattering study by Majerus et al. showed that $N_{4}$ decreases progressively from $\mathrm{Li}$ to $\mathrm{K}$ for alkali borate glasses with composition $x=0.33$. $^{24}$

The structure of cesium borate glasses was reinvestigated recently by Berryman et al. employing ${ }^{11} \mathrm{~B}$ NMR spectroscopy. ${ }^{25}$ It was found that the $N_{4}$ values for Cs borate glasses follow closely those determined for glasses in the $\mathrm{Li}$ borate system, while in the earlier Zhong and Bray study a clear difference was revealed in $N_{4}$ values between the two systems. ${ }^{16,17}$ Kodama and Kojima ${ }^{26}$ reported high-precision ultrasonic velocity data for $\mathrm{Cs}$ and $\mathrm{Li}$ borate glasses and modeled the elastic properties in terms of the population and elastic constants of three local structural units: $\mathrm{B} \emptyset_{3}, \mathrm{~B} \varnothing_{4}^{-} \mathrm{M}^{+}$, and $\mathrm{B}_{2} \mathrm{O}^{-} \mathrm{M}^{+}$. Their property-structure analysis showed that the $N_{4}$ parameter follows the relation $N_{4}=x /(1-x)$ for $\mathrm{Li}$ borates in the range $0 \leqslant x \leqslant 0.28$ and deviates from this relation at higher lithium contents. This suggests that the conversion of $\mathrm{B} \emptyset_{3}$ to $\mathrm{B} \varnothing_{4}^{-}$units takes place for compositions up to ca. $x=0.28$, and this process is followed by the decay of $\mathrm{B} \emptyset_{4}^{-}$ and the formation of $\mathrm{B}_{2} \mathrm{O}^{-}$units for $x>0.28$. The results obtained for Cs borate glasses were quite distinct in that the deviation of $N_{4}$ from the $x /(1-x)$ relation was observed at very low $\mathrm{Cs}_{2} \mathrm{O}$ contents, i.e., at ca. $x=0.065$. $^{26}$ This finding was taken to demonstrate a larger tendency of Cs borate glasses for nonbridging oxygen formation in comparison to Li borates of the same alkali content. In view of these points, we note that a recent ${ }^{11} \mathrm{~B}$ magic-angle spinning (MAS) NMR study by Clarida et ll $^{27}$ of borate glasses with alkali content $x=0.286$ has suggested that $N_{4}$ has little or no dependence on the type of alkali metal, though the measured values are systematically higher than 0.40 , corresponding to the $x /(1-x)$ value. It is apparent that more work is required in this field to shed light on the structural peculiarities exhibited by modified borate glasses.

We have recently employed molecular-dynamics (MD) simulations to investigate structural aspects and ion dynamics in Li borate glasses. ${ }^{28-30}$ The analysis of the MD data allowed the evaluation of the relative population of the local structural units as a function of lithium oxide content and temperature. In addition, the microstructure of sites hosting $\mathrm{Li}$ ions was studied, and the corresponding Li ion site vibrational response was computed and compared with experimental far-infrared spectra. In this work we extend our MD studies to cesium borate glasses $x \mathrm{Cs}_{2} \mathrm{O}-(1-x) \mathrm{B}_{2} \mathrm{O}_{3}$ as a function of composition $(x=0.2,0.3$, and 0.4$)$ and temperature $(T=300$ and $1250 \mathrm{~K})$. In the first part of the work we focus on the structure of the simulated glasses, expressed by the molar fractions of the short-range-order (SRO) structural units, and on the dependence of this structure on composition and temperature. The results are compared with those obtained for Li borate glasses under similar conditions in order to search for any influence of the alkali metal ion on the SRO structure of a glass. The structural information is subsequently employed to determine the types of site occupied by Cs ions and to calculate the short-time dynamics related to the rattling motion of $\mathrm{Cs}$ ions in their local sites. The results are discussed in comparison with previous reports on the structure and properties of glasses in the Cs borate system.

\section{COMPUTATIONAL METHOD}

The MD simulations were performed on a collection of ca. 512 atoms in a primitive cubic lattice, with lattice parameters calculated from the experimental density data of $\mathrm{Cs}$ borate glasses. $^{31-33}$ Interatomic interactions were treated by means of the usual Born-Mayer-Huggins potential, ${ }^{21}$

$$
V_{i j}(r)=A_{i j} \exp (-r / \rho)+z_{i} z_{j} e^{2} / r
$$

where

$$
A_{i j}=20.3545\left(1+\frac{z_{i}}{\eta_{i}}+\frac{z_{j}}{\eta_{j}}\right) \exp \left(\frac{r_{i}+r_{j}}{\rho}\right) \quad(\mathrm{kJ} / \mathrm{mol}) .
$$

In Eqs. (1) and (2), $z_{i} e$ and $z_{j} e, \eta_{i}$ and $\eta_{j}$, and $r_{i}$ and $r_{j}$ are the charges, number of valence shell electrons, and ionic radii of ions $i$ and $j$, respectively, and $\rho$ is the repulsion parameter $(\rho=0.29 \AA)$.

The charge of the Cs ion is taken equal to 1 , whereas charges for boron and oxygen atoms are calculated from the following equations:

$$
\begin{aligned}
& Z_{\mathrm{B}}=2.0-0.5 \frac{N_{\mathrm{Cs}}}{N_{\mathrm{B}}}(1-\kappa), \\
& Z_{\mathrm{O}}=-1.333-0.5 \frac{N_{\mathrm{Cs}}}{N_{\mathrm{O}}}(1-\kappa),
\end{aligned}
$$

where $\kappa=0.667$ is a charge scaling factor that yields a partial covalent character of the B-O interactions so that the simulated vibrational spectra have a close agreement with the experimental ones. ${ }^{21} N_{\mathrm{Cs}}, N_{\mathrm{O}}$, and $N_{\mathrm{B}}$ are the number of $\mathrm{Cs}$, $\mathrm{O}$, and $\mathrm{B}$ atoms in a specific simulated glass composition.

An additional three-body harmonic interaction potential term for the $\mathrm{O}-\mathrm{B}-\mathrm{O}$ angles was included,

$$
V_{i j k}=0.5 K_{i j k}\left(\theta-\theta_{0}\right)^{2} \text {, }
$$

where $K_{i j k}$ is a constant determining the strength of the interaction and $\theta$ is the angle between $i-j$ and $j-k$ bonds, where $i$ and $k$ are the oxygen atoms bonded to the $j$ th boron atom. The angle $\theta_{0}$ corresponds to the expected angle value for ideal triangular $\left(\theta_{0}=120^{\circ}\right)$ and tetrahedral $\left(\theta_{0}=109.47^{\circ}\right)$ borate units. The constant $K_{i j k}$ assumes different values when it refers to tetrahedral $\left(K_{i j k}=1000 \mathrm{~kJ} /\left(\mathrm{mol} \mathrm{rad}^{2}\right) \quad\right.$ and triangular $\left(K_{i j k}\right.$ $=500 \mathrm{~kJ} /\left(\mathrm{mol} \mathrm{rad}^{2}\right)$ borate units. These values were determined by following the same reasoning as that for the charge scaling parameter $\kappa$. The values of parameters which appear in Eqs. (1) and (2) are summarized in Table I. 
TABLE I. Values of ionic radii $r_{i}$ and valence electrons $\eta_{i}$ for the interatomic potential in Eqs. (1) and (2).

\begin{tabular}{ccc}
\hline \hline & $\begin{array}{c}r_{i} \\
(\AA)\end{array}$ & $\eta_{i}$ \\
\hline $\mathrm{B}$ & 0.770 & $5-z_{\mathrm{B}}$ \\
$\mathrm{O}$ & 1.265 & $6-z_{\mathrm{O}}$ \\
$\mathrm{Cs}$ & 1.840 & 8 \\
\hline \hline
\end{tabular}

The simulations were carried out in the canonical ensemble, where the initial configuration was generated from a random distribution of atoms over the sites of the fcc lattice with velocities taken from a Maxwellian distribution at 5000 K. Periodic boundary conditions were applied, and longrange Coulombic forces were handled by employing the Ewald summation method. ${ }^{34} \mathrm{~A}$ fifth-order Gear predictorcorrector integrator with a time step of $0.96 \mathrm{fs}$ was used.

The generated melts were quenched from an initial temperature of $5000 \mathrm{~K}$ to the final temperatures of 300 or 1250 $\mathrm{K}$ in five or three cooling cycles, respectively, where at each cycle the temperature was fixed and set equal to half of the value it had in the previous cycle. At a particular cooling cycle, temperature was monitored and kept constant for about 2 ps by scaling down the velocities of the particles at each time step, followed by another time period of $10 \mathrm{ps}$ where, this time, the velocities were scaled down for every 10 time steps. In the final cooling cycle the 10-ps time period was extended to $30 \mathrm{ps}$, after which properties were accumulated for a final period of about 180 ps.

The simulated final temperatures of 300 and $1250 \mathrm{~K}$ correspond to the glassy state, although we have not performed calculations for the location of the exact melting point. This stems from the fact, in particular for the 1250-K temperature, that the mean-square displacement (MSD) curves of the oxygen and boron atoms are practically straight lines with a slope very close to zero. In a melt, the atoms of the network structure are expected to be more mobile. The choice of the $1250-\mathrm{K}$ temperature was more or less arbitrary, and it was based on the fact that we wanted to study the temperatureinduced structural changes as well as the dynamics of Cs ions not included in the present work. In a room-temperature simulated glass, the dynamics are extremely slow to be followed in a reasonable computational time.

\section{RESULTS AND DISCUSSION}

\section{A. Composition and temperature dependence of the short-range order structure}

The boron-oxygen radial distribution functions (RDFs) of the simulated $x \mathrm{Cs}_{2} \mathrm{O}-(1-x) \mathrm{B}_{2} \mathrm{O}_{3}$ glasses were calculated at temperatures of 300 and $1250 \mathrm{~K}$ in order to determine the short-range order structure of the borate network. Typical results concerning the first peak in the boron-oxygen RDF $g_{\mathrm{B}-\mathrm{O}}(R)$ are shown in Fig. 1 and are compared with corresponding RDFs obtained previously for Li borate glasses. ${ }^{29}$ This first peak in the $g_{\mathrm{B}-\mathrm{O}}(R)$ arises from the nearestneighbor $\mathrm{B}-\mathrm{O}$ correlations and should be taken as resulting from the overlapping contributions of $\mathrm{B}-\mathrm{O}$ distances in $\mathrm{SRO}$ units, i.e., borate triangles $\left(\mathrm{B}_{3}, \mathrm{~B}_{2} \mathrm{O}^{-}\right.$, and $\left.\mathrm{B} \mathrm{O}_{2}^{2-}\right)$ and

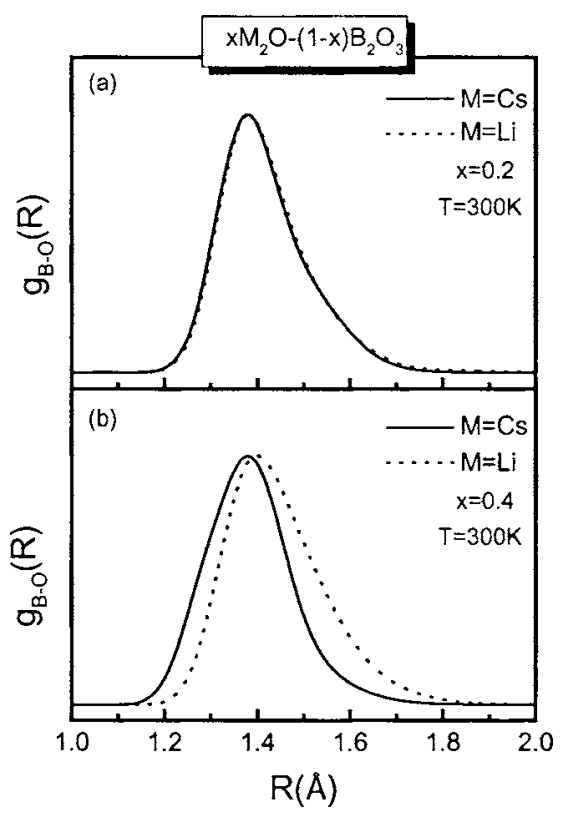

FIG. 1. The first peak of the boron-oxygen radial distribution functions at $300 \mathrm{~K}$ for simulated $x M_{2} \mathrm{O}-(1-\mathrm{x}) \mathrm{B}_{2} \mathrm{O}_{3}$ glasses $(M=\mathrm{Cs}, \mathrm{Li}$, and $x=0.2,0.4)$.

tetrahedra $\left(\mathrm{B} \emptyset_{4}^{-}\right)$. The presence of borate triangles and tetrahedra as the network building blocks is consistent with the $\mathrm{O}-\mathrm{B}-\mathrm{O}$ angle distribution functions which exhibit sharp peaks at ca. $120^{\circ}$ and $110^{\circ}$ for all compositions and temperatures investigated.

For the composition $x=0.2$ the first peak of $g_{\mathrm{B}-\mathrm{O}}(R)$ is practically independent of the nature of the alkali ion [Fig. 1(a)], implying very similar SRO structures for the two glasses. However, at higher alkali contents the fist peak exhibits a metal ion dependence as observed in Fig. 1(b) for $x=0.4$. For $M=\mathrm{Cs}$ the first peak appears shifted to lower $\mathrm{B}-\mathrm{O}$ distances compared to those for $M=\mathrm{Li}$. This peak originates from three different contributions corresponding to $\mathrm{B}(3)-\mathrm{NBO}$ bonds, B(3)- $\varnothing$ bonds, and B(4)- $\varnothing$ bonds, where the number in parentheses denotes the coordination of the boron atom. Since the B(3)-NBO bonds are shorter than the $\mathrm{B}(3)-\varnothing$ bonds, which in turn are shorter than the $\mathrm{B}(4)-\varnothing$ bonds, ${ }^{21,22}$ we infer that the $x=0.4$ Cs borate glass exhibits a smaller relative population of $\mathrm{B} \emptyset_{4}^{-}$units and a larger abundance of NBO-containing units than does its Li counterpart.

To quantify the above observations we proceed with the evaluation of the molar fraction of the SRO structural units constituting the borate network. From the integration of the first peak of $g_{\mathrm{B}-\mathrm{O}}(R)$ (Fig. 1) up to the first minimum, the average coordination number of boron $\langle\mathrm{B}(\mathrm{O})\rangle$ is obtained, and this leads to the fraction of the $\mathrm{B} \varnothing_{4}^{-}$tetrahedra by the simple relation $X_{4}=\langle\mathrm{B}(\mathrm{O})\rangle-3$. The results are displayed in Fig. 2 where they are compared with the theoretical curve $x /(1-x)$, the room-temperature NMR data for Cs borate glasses, ${ }^{16,25}$ and the $X_{4}$ data from the MD simulation of $\mathrm{Li}$ borate glasses. ${ }^{28,29}$ At $T=300 \mathrm{~K}$ both experimental and MDderived $X_{4}$ values deviate from the theoretical curve, and this effect becomes more pronounced for the $x=0.3$ and $0.4 \mathrm{Cs}$ borate compositions, implying an increasing fraction of NBO-containing units at these higher Cs modification levels.

The presence of NBOs at $T=300 \mathrm{~K}$ for $x=0.3$ and 0.4 


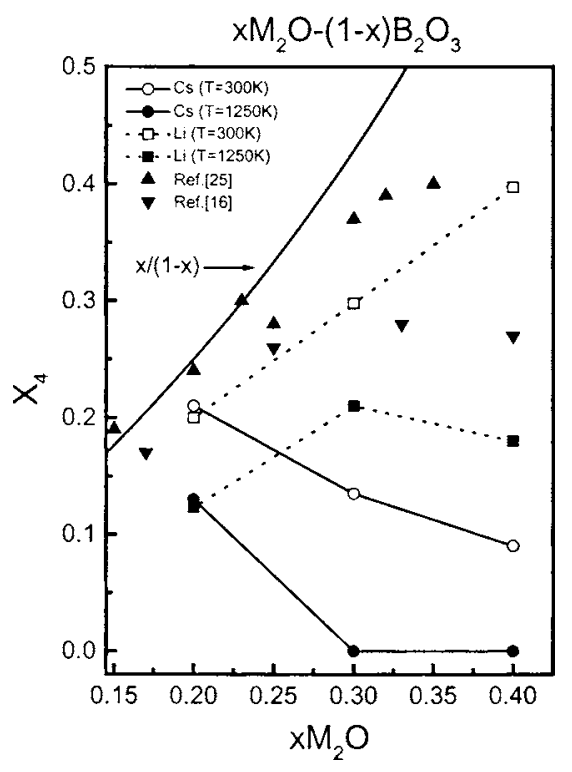

FIG. 2. Molar fraction of $\mathrm{B}_{4}^{-}$tetrahedral units, $X_{4}$, in simulated $\mathrm{Cs}$ and $\mathrm{Li}$ borate glasses as a function of composition and temperature. Experimental room-temperature NMR data reported for Cs borate glasses are also included (Refs. 16 and 24). The $x /(1-x)$ curve gives the $X_{4}$ fraction if $\mathrm{B} \emptyset_{4}^{-}$ tetrahedra are the only charged units existing in borate glasses.

could be responsible also for the larger differences in $X_{4}$ observed between experimental and MD data. As discussed by Soules ${ }^{35}$ and others, ${ }^{21,22}$ the very high cooling rates involved in MD simulations lead to simulated glasses having higher fictive temperatures with typical laboratory glasses. The result of this effect is that a simulated glass reflects the quasiequilibrium structure arrested at high temperatures. As shown by statistical-mechanical calculations ${ }^{36}$ and by spectroscopic techniques, such as $\mathrm{NMR},{ }^{37}$ infrared, ${ }^{38} \mathrm{x}$-ray diffraction, ${ }^{39}$ and Raman, ${ }^{40}$ the NBO-containing triangular units of modified borate glasses are favored at high temperatures at the expense of the $\mathrm{B} \emptyset_{4}^{-}$tetrahedra. A similar effect of temperature was found in a recent MD simulation of a $\mathrm{B}_{2} \mathrm{O}_{3}$ glass, in the sense that the maximum fraction of boroxol rings (ca. 33\%) was observed when the simulated glass was "prepared" at low temperatures. ${ }^{41}$ However, the nonring $\mathrm{B}_{3}$ triangles were found to be favored at higher equilibration temperatures at the expense of boroxol rings, the fraction of which drops to ca. $11 \% .^{41}$ Therefore, it is reasonable to find that simulated Cs borates exhibit at $300 \mathrm{~K}$ lower $X_{4}$ values than do laboratory glasses investigated by room-temperature NMR, provided that the alkali content favors the formation of NBOs (i.e., compositions $x=0.3,0.4$ ).

As shown in Fig. 2, the structural parameter $X_{4}$ derived by $\mathrm{MD}$ at $300 \mathrm{~K}$ for the composition with the lower Cs content $(x=0.2)$ is practically the same as that obtained by room-temperature NMR. ${ }^{16,25}$ This can be attributed to the fact that the smaller NBO concentration makes the $x=0.2$ glass structure less vulnerable to the large differences in quenching rates existing between simulated and laboratory glasses. This finding is in accord with the high-temperature Raman study of Akagi et al. on $\mathrm{K}$ borate glasses. ${ }^{40}$ They have demonstrated that the Raman profiles of the $x$ $=0.3$ glass $/ \mathrm{melt}$ are much more sensitive to temperature changes than those of the $x=0.2$ glass $/$ melt.
It is clear from the above discussion that a comparison of the $X_{4}$ data on laboratory glasses from MD simulations with those from NMR spectroscopy should be made with caution. Therefore, we suggest that it is preferable to consider trends of $X_{4}$ rather than absolute values when discussing the structure of simulated glasses. In this context, the MD data in Fig. 2 indicate that for $x=0.2$ similar SRO structures exist in $\mathrm{Li}$ and Cs borate glasses, in agreement with the NMR findings of Berryman et al. ${ }^{25}$ However, the results of the simulations for glasses of higher metal oxide contents $(x=0.3,0.4)$ indicate larger fractions of NBO-containing units in Cs glasses, in agreement with the NMR work of Zhong and Bray ${ }^{16}$ and Bray, ${ }^{17}$ the suggestions of Kodama and Kojima, ${ }^{26}$ and the trend found in the neutron-scattering study of Majerus et al. for diborate glasses $(x=0.33){ }^{24}$

The effect of temperature on structure is studied here by "preparing" simulated Cs borate glasses at $1250 \mathrm{~K}$. In comparison with the MD data at $300 \mathrm{~K}$ (Fig. 2) it is clear that $X_{4}$ decreases with increasing temperature for all Cs borate compositions, in agreement with our earlier simulations of $\mathrm{Li}$ borate glasses ${ }^{28,29}$ and neutron-scattering experiments on alkali diborate glasses. ${ }^{24}$ The effect of temperature is particularly drastic for Cs contents $x=0.3$ and 0.4 , since for these compositions the $\mathrm{B} \emptyset_{4}^{-}$tetrahedra have been completely transformed into NBO-containing borate triangular units at $1250 \mathrm{~K}$. The nature of these latter units will be discussed in the following section.

Such a change in boron speciation with temperature is expected to contribute largely to the configurational entropy of the system, and, thus, it should manifest itself in structurerelated properties including ion transport and viscous flow. ${ }^{37}$ Indeed, even in early studies ${ }^{9}$ the transformation of the $\mathrm{B} \emptyset_{4}^{-}$ tetrahedra into triangles with $\mathrm{NBO}$ atoms was correlated with the reduction of network crosslinking and the consequent reduction of viscosity. More recently, Angell introduced the concept of "strength and fragility" to classify glass-forming liquids in terms of their temperature dependence on viscosity $\eta .^{42}$ A convenient measure of the ease with which the structure changes with temperature ("fragility" index) is the slope of the $\log \eta$ versus the $T_{g} / T$ curve in the vicinity of glass transition (i.e., $S$ $=\lim _{T_{g} / T \rightarrow l} d \log \eta / d\left(T_{g} / T\right)$ ), as this quantity is proportional to an activation energy for viscous flow. The fragility index has been determined for Li borate glasses and was found to increase with increasing alkali oxide content. ${ }^{43}$ In a similar approach, the activation entropy at the glass transition was used as a measure of the fragility of the system and was found also to increase with increasing alkali content in borate glasses. ${ }^{44}$ These trends can be attributed at large to an increasing effect of temperature on the change of boron coordination from four to three with increasing alkali content as found in the MD simulations of Cs and Li borates.

\section{B. Nonbridging oxygen (NBO)-containing borate units and NBO-NBO correlations}

Considering the important role of NBOs in metal ion network bonding and transport properties, ${ }^{29,45,46}$ it is of interest to examine the nature of NBO-containing structural 

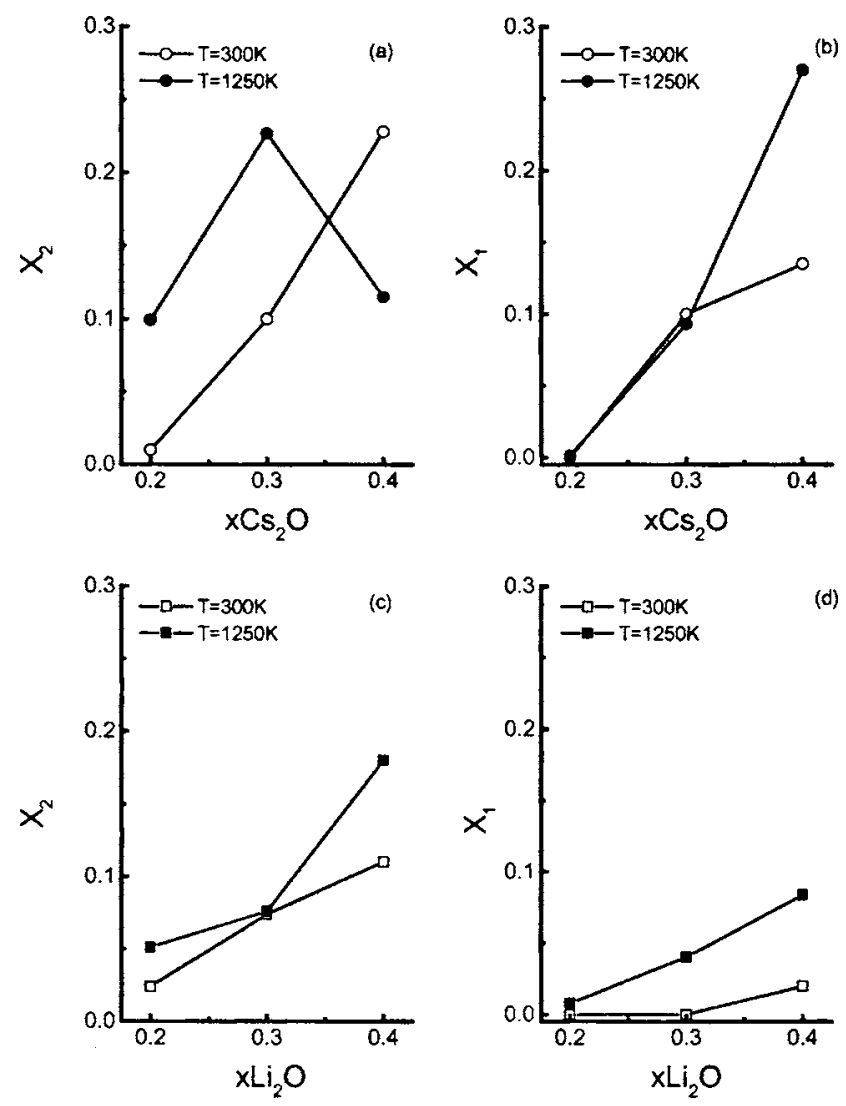

FIG. 3. Molar fractions of $\mathrm{B}_{2} \mathrm{O}^{-}\left(X_{2}\right)$ and $\mathrm{B} \mathrm{O}_{2}^{2-}\left(X_{1}\right)$ units in simulated $\mathrm{Cs}$ and $\mathrm{Li}$ borate glasses as a function of alkali content and temperature.

units in simulated Cs borate glasses. For the compositions investigated in this work the charged triangular borate units are those with one NBO $\left(\mathrm{B}_{2} \mathrm{O}^{-}\right)$and two NBOs per boron

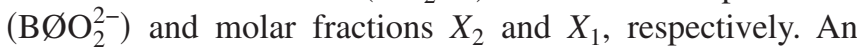
oxygen atom is identified as NBO if no other boron atom is found within a sphere of ca. $2 \AA$ radius. This cutoff distance corresponds to the first minimum of the B-O RDF curve, and it is found to be almost temperature and composition independent. Having determined the total number of NBO atoms in the simulated box, the fractions $X_{2}$ and $X_{1}$ were derived using the procedure described previously in detail. ${ }^{29}$ The obtained fractions $X_{2}$ and $X_{1}$ are presented in Figs. 3(a) and 3(b) as functions of composition and temperature and are compared with the data for Li borate glasses in Figs. 3(c) and 3(d). It is evident that for $x=0.2$ the increase in temperature results in the transformation of $\mathrm{B} \varnothing_{4}^{-}$units into triangular $\mathrm{B}_{2} \mathrm{O}^{-}$units (fraction $X_{2}$ ) for both glass systems. This temperature effect on SRO speciation can be described by the isomerization reaction,

$$
\mathrm{B} \emptyset_{4}^{-} \Leftrightarrow \mathrm{B} \varnothing_{2} \mathrm{O}^{-},
$$

which shifts to the right with increasing temperature. ${ }^{36-40}$

The conversion of $\mathrm{B} \varnothing_{4}^{-}$tetrahedra into $\mathrm{B} \varnothing_{2} \mathrm{O}^{-}$and $\mathrm{B} \mathrm{O}_{2}^{2-}$ units is favored in both systems upon increasing temperature when $x>0.2$, with $\mathrm{Cs}$ borate glasses exhibiting larger $X_{2}$ and $X_{1}$ values than do their Li borate counterparts (Fig. 3). While the formation of $\mathrm{B}_{2} \mathrm{O}^{-}$is understood in terms of equilibrium (6), the creation of the doubly charged $\mathrm{B} \varnothing \mathrm{O}_{2}^{2-}$ units at high temperatures can result from the disproportionation reaction,

$$
2 \mathrm{~B} \varnothing_{4}^{-} \Leftrightarrow \mathrm{B} \varnothing \mathrm{O}_{2}^{2-}+\mathrm{B} \varnothing_{3},
$$

which was found to operate in magnesium borate glasses. ${ }^{47}$

Room-temperature Raman studies ${ }^{48,49}$ of Cs borate glasses have shown that in the range $0.3 \leqslant x \leqslant 0.5$ the negative charge is located mainly on the metaborate species, i.e., on tetrahedra $\mathrm{B}_{4}^{-}$and $\mathrm{B}_{2} \mathrm{O}^{-}$triangles, the latter being organized mostly into metaborate rings $\mathrm{B}_{3} \mathrm{O}_{6}^{3-}$, through the following equilibrium reaction:

$$
3 \mathrm{~B}_{2} \mathrm{O}^{-} \Leftrightarrow \mathrm{B}_{3} \mathrm{O}_{6}^{3-} \text {. }
$$

For $\mathrm{Cs}_{2} \mathrm{O}$ contents approaching the metaborate composition $(x=0.5)$ the room-temperature Raman spectra suggested also the presence of a small concentration of pyroborate dimers

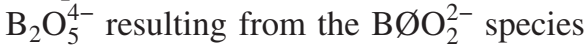

$$
2 \mathrm{~B} \varnothing \mathrm{O}_{2}^{2-} \Leftrightarrow \mathrm{B}_{2} \mathrm{O}_{5}^{4-} \text {. }
$$

Since Figs. 3(a) and 3(b) suggest that species $\mathrm{B}_{2} \mathrm{O}^{-}$ and $\mathrm{B} \varnothing \mathrm{O}_{2}^{2-}$ exist in considerable concentrations at high $\mathrm{Cs}_{2} \mathrm{O}$ contents and temperatures, we search now for the possibility of these SRO units being organized into well-defined medium-range-order (MRO) structures like ring and dimer types expressed by reactions (8) and (9), respectively. For this purpose, we have counted all possible structural configurations of two interconnected borate triangular units, with at least one of them being charged. These structures are termed as $(i-j)$, where $i$ and $j$ indicate the number of NBOs per borate triangle. For example, in the structure (1-2) the first triangle has one $\mathrm{NBO}$ and the second one two. For the $x$ $=0.2$ composition practically all $\mathrm{B}_{2} \mathrm{O}^{-}$units were found in configuration 1-0. For $\mathrm{Cs}_{2} \mathrm{O}$ contents larger than $x=0.2$ the configuration 1-0 is still present, and types 1-1, 2-0, and 1-2 are also formed in percentages depending on temperature and composition. However, no tendency was found for the formation of metaborate rings or pyroborate dimers (structure 2-2) at any composition and temperature studied here. This reinforces the fact expressed above that simulated Cs borate glasses have much higher fictive temperatures than laboratory glasses, and, thus, equilibria (8) and (9) are shifted to the left in simulated glasses. This result is analogous to that reported for glassy $\mathrm{B}_{2} \mathrm{O}_{3}$ where the boroxol rings (MRO structures) were found to be dismantled into $\mathrm{B} \varnothing_{3}$ triangles (SRO species) when the glass is prepared at high temperatures. $^{41}$

Further insights into the relative organization of the NBO-containing triangles in glass can be obtained from the consideration of the NBO-NBO correlation functions, an example of which is displayed in Fig. 4 for the $x=0.3 \mathrm{Cs}$ and $\mathrm{Li}$ borate compositions at $T=1250 \mathrm{~K}$. The first narrow peak at ca. $2.25 \AA$ can be attributed to correlations between NBO atoms belonging to the same triangular unit, ${ }^{29}$ and its area is connected directly to the number of $\mathrm{B} \varnothing \mathrm{O}_{2}^{2-}$ units. A comparison of the two glasses shows that the Cs borate peak is shifted to a smaller distance, suggesting differences in bonding in the two glass systems. In particular, since the $\mathrm{O}-\mathrm{B}-\mathrm{O}$ angles of the triangular borate units remain the same in the 


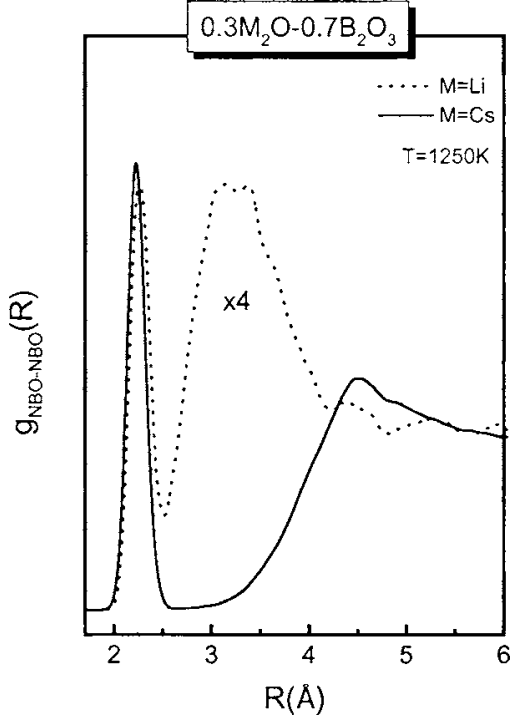

FIG. 4. NBO-NBO correlation functions for $\mathrm{Li}$ and $\mathrm{Cs}$ borate glasses of composition $0.3 M_{2} \mathrm{O}-0.7 \mathrm{~B}_{2} \mathrm{O}_{3}$ and temperature $T=1250 \mathrm{~K}$. The curves are normalized to the average total number of NBO atoms. The RDF curve for $M=\mathrm{Li}$ is multiplied by four for clarity.

two systems, the smaller NBO-NBO distance found for Cs borates should be attributed to a corresponding smaller $\mathrm{B}-\mathrm{NBO}$ distance. This result is consistent with the smaller field strength of $\mathrm{Cs}$ ion compared to $\mathrm{Li}$, that leads to weaker Cs ion-oxygen interactions and, thus, to a relatively stronger $\mathrm{B}-\mathrm{NBO}$ bonding in $\mathrm{Cs}$ glasses. As a result, the overall boron-oxygen bonding in glasses containing NBOs is expected to be stronger in $\mathrm{Cs}$ than in Li borates, and this is demonstrated clearly by the first peak of the B-O RDF in Fig. 1(b).

More pronounced differences in the NBO-NBO RDFs of two glass systems are observed at larger $R$ values, where the strong peak at ca. $3.3 \AA$ observed for the Li borate glass appears to be missing for $M=C$ s. In our previous work ${ }^{29}$ the 3.3- $\AA$ peak was attributed to correlations between NBOs in connected borate triangles, like the structural arrangement ${ }^{-} \mathrm{O} \emptyset \mathrm{B} \emptyset \mathrm{B} \varnothing \mathrm{O}^{-}$found in Cs borates (configuration 1-1). However, the absence of such a peak in the Cs borate NBO-NBO correlations necessitates the reevaluation of our previous assignment. For this purpose we have calculated separately the NBO-NBO RDFs for NBO atoms belonging to connected triangular units (configurations 1-1 and 1-2), as well as to unconnected $\mathrm{B}_{2} \mathrm{O}^{-}$triangular units. The results for the $x$ $=0.3 \mathrm{Li}$ glass at $T=1250 \mathrm{~K}$ are shown in Fig. $5(\mathrm{a})$, where it is clearly shown that the major contribution to $3.3 \AA$ comes from NBO-NBO correlations in unconnected $\mathrm{B}_{2} \mathrm{O}^{-}$units (noted by unc in Fig. 5), with such NBOs participating most likely in the coordination sphere of the same $\mathrm{Li}$ ion. Therefore, the high intensity of the $3.3-\AA$ peak is another manifestation of the NBO clustering observed in Li borate glasses. ${ }^{29}$ Interesting enough, the NBO atoms in connected borate triangles contribute mainly at ca. $4.4 \AA$ and give rise to the small peak observed at this range in the total NBO-NBO RDF.

For the Cs-containing glass the NBO-NBO pair correlations in configurations $1-1$ and $1-2$ are found to peak also

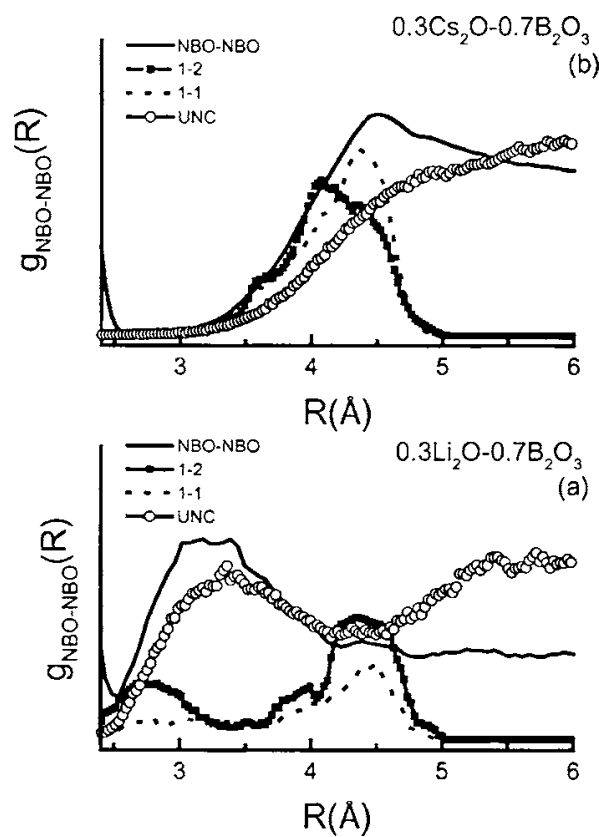

FIG. 5. NBO-NBO correlation functions for the $0.3 M_{2} \mathrm{O}-0.7 \mathrm{~B}_{2} \mathrm{O}_{3}$ glass at $T=1250 \mathrm{~K}$ with $M=\mathrm{Li}$ (a) and $M=\mathrm{Cs}$ (b). Partial NBO-NBO RDF curves for configurations 1-1 and 1-2 shown in Fig. 4 also included, while the partial denoted by unc corresponds to unconnected triangular $\mathrm{B}_{2} \mathrm{O}^{-}$units. The partial RDF curves are magnified for clarity.

between 4 and $4.5 \AA$ [Fig. 5(b)]. However, the NBO-NBO correlation function between unconnected triangular units in the Cs glass gives an increasing contribution for distances above ca. $3.5 \AA$, instead of the peak observed for $M=\mathrm{Li}$. This shows that the most probable distances between NBO atoms belonging to unconnected $\mathrm{B}_{2} \mathrm{O}^{-}$configurations become now significantly larger because of the larger ionic radius of $\mathrm{Cs}$, and, thus, the shell corresponding to second neighbors is not well defined.

\section{Cs ion hosting sites and their short-time dynamics}

The structural differences discussed above between Cs and $\mathrm{Li}$ borates are expected to be reflected on the metal ionoxygen bonding characteristics. Such differences are revealed by the total alkali metal-oxygen pair radial distribution functions $g_{M-O}(R)$, which are found to peak at $3.25 \AA$ for $M=\mathrm{Cs}$ and at $2.12 \AA$ for $M=\mathrm{Li}$ for the room-temperature simulated glasses.

Further distinction can be made on the basis of the nature of oxygen atoms forming the coordination environment/ site of the metal ion. In the previous work ${ }^{29}$ we have shown that metal ion hosting sites can be classified according to whether they consist exclusively of bridging oxygen atoms (b-type sites) or of both bridging and nonbridging oxygen atoms (nb-type sites). Based on this classification we label individual $\mathrm{Cs}$ ions as $\mathrm{Cs}^{b}$ or $\mathrm{Cs}^{\mathrm{nb}}$ if they reside predominantly (i.e., more than $75 \%$ of the simulation time) in $b$ - or nb-type sites, respectively. The Cs ions which do not fulfill this criterion are considered mixed $\mathrm{Cs}^{m}$. The fractions of $\mathrm{Cs}^{b}, \mathrm{Cs}^{\mathrm{nb}}$, and $\mathrm{Cs}^{m}$ ions have been evaluated, and the results are presented in Fig. 6 as functions of composition and temperature. The population of the $\mathrm{Cs}^{\mathrm{nb}}$ ions is found to increase with $\mathrm{Cs}_{2} \mathrm{O}$ content and temperature at the expense of the $\mathrm{Cs}^{b}$ 


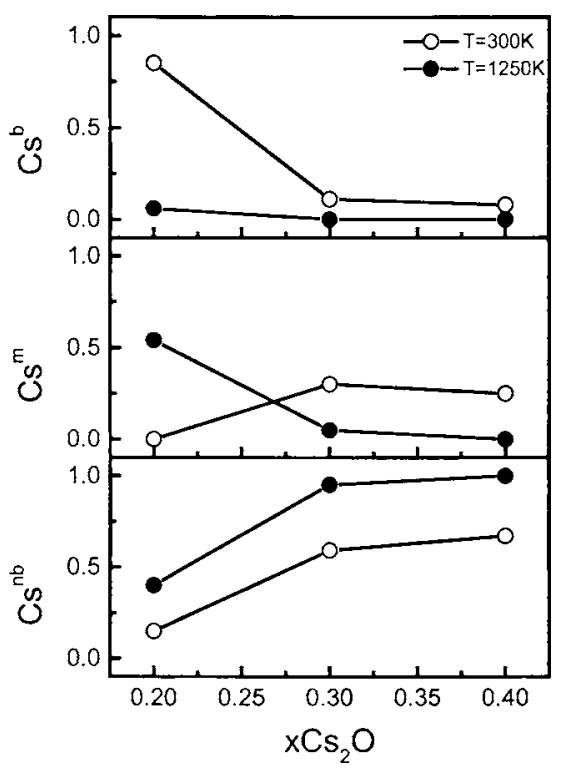

FIG. 6. Composition and temperature dependence of the mole fractions of Cs ions occupying different types of network sites: $b$ type $\left(\mathrm{Cs}^{b}\right)$ nb type $\left(\mathrm{Cs}^{\mathrm{nb}}\right)$, and mixed type $\left(\mathrm{Cs}^{m}\right)$. For details on the nature of the Cs ion hosting sites see text.

fraction. This result is in agreement with the progressive transformation of the $\mathrm{B}_{4}^{-}$tetrahedra into $\mathrm{NBO}$-containing triangles upon increasing $\mathrm{Cs}_{2} \mathrm{O}$ content and temperature, as discussed above.

From Fig. 6 we infer that the $\mathrm{B}_{4}^{-}$units are less effective than the NBO-containing units in retaining $\mathrm{Cs}$ ions in their vicinity for the entire simulation time. To support this argument we examine the $x=0.3$ and 0.4 compositions at $T$ $=300 \mathrm{~K}$ where a sufficient NBO concentration is present. If we suppose that each $\mathrm{B} \varnothing_{4}^{-}$unit is associated with one $\mathrm{Cs}$ ion, then the $\mathrm{Cs}^{b}$ fractions should be 0.30 and 0.15 for $x=0.3$ and $x=0.4$, respectively, according to the percentage of the $\mathrm{B} \emptyset_{4}^{-}$ tetrahedra with respect to the total negative charge, $x /(1$ $-x$ ). However, we find that the corresponding fractions for $\mathrm{Cs}^{b}$ are 0.11 and 0.08 (Fig. 6). Similarly, the $\mathrm{Cs}^{\mathrm{nb}}$ fractions would be 0.70 and 0.85 if each $\mathrm{NBO}$ atom were associated with one Cs cation. Instead, we find from Fig. 6 that the $\mathrm{Cs}^{\mathrm{nb}}$ fractions are 0.60 and 0.67 . Thus, there is a roughly $50 \%$ deviation of the calculated $\mathrm{Cs}^{b}$ fractions from the expected ones, while the corresponding deviation of the $\mathrm{Cs}^{\mathrm{nb}}$ fraction is about $20 \%$. These deviations are compensated by the presence of a significant number of Cs ions in mixed sites $\left(\mathrm{Cs}^{m}\right.$ ions in Fig. 6). These findings suggest that Cs ions are loosely bonded to $\mathrm{B} \varnothing_{4}^{-}$tetrahedral units, and they are dragged to mixed-type environments consisting of both $\mathrm{B} \varnothing_{4}^{-}$ and NBO-containing units.

The situation is different for the $x=0.2$ Cs borate composition at $T=300 \mathrm{~K}$, where the $\mathrm{B} \varnothing_{4}^{-}$tetrahedral units constitute the vast majority of the charged species (85\%). We find in this case that there is a one-to-one correspondence between $\mathrm{B} \varnothing_{4}^{-}$tetrahedral and $\mathrm{Cs}^{b}$ ions, as well as between $\mathrm{NBO}$ atoms and $\mathrm{Cs}^{\mathrm{nb}}$ ions. This is attributed to the reduced probability of a $\mathrm{B}_{4}^{-}$tetrahedron to be in the neighborhood of a NBO atom when the alkali content and temperature are considerably low. On the other hand, NBO-containing units are able to retain $\mathrm{Cs}$ ions in their neighborhood despite the fact that they are minority borate species, probably a result of their higher charge density with respect to $b$-type sites.

A similar analysis for Li borate glasses ${ }^{29}$ shows that at $T=300 \mathrm{~K}$ the population of $\mathrm{Li}^{b}$ ions is considerably smaller than the population of $\mathrm{B} \varnothing_{4}^{-}$units, whereas the population of $\mathrm{Li}^{\mathrm{nb}}$ ions is systematically larger than the number of NBO atoms. This effect was associated with a tendency of the nonbridging oxygen atom to coordinate more than one $\mathrm{Li}$ ion. However, as we have seen above such a trend for NBO/ metal ion clustering does not seem to be pronounced in $\mathrm{Cs}$ borate glasses.

The classification of $\mathrm{Cs}$ ions according to the site where they predominantly reside and the use of the relevant pair radial distribution functions permit the evaluation of the corresponding coordination numbers with oxygen, $\mathrm{Cs}^{\mathrm{nb}}(\mathrm{O})$ and $\mathrm{Cs}^{b}(\mathrm{O})$. It is noted that for $\mathrm{Li}$ borate glasses the $\mathrm{Li}^{\mathrm{nb}}-\mathrm{O}$ and $\mathrm{Li}^{b}-\mathrm{O}$ partial RDFs show considerable differences regarding their shape and the position of the first peak (1.92 and 2.12 $\AA$, respectively). ${ }^{29}$ In the present case, however, the $\mathrm{Cs}^{\mathrm{nb}}-\mathrm{O}$ and $\mathrm{Cs}^{b}-\mathrm{O}$ partial RDFs show their first peak at approximately the same position as the total Cs-O RDF (ca. $3.25 \AA$ ), the only difference being that the $\mathrm{Cs}^{\mathrm{nb}}-\mathrm{O} \mathrm{RDF}$ is better defined than the $\mathrm{Cs}^{b}-\mathrm{O}$ partial. Consequently, for $x=0.3$ and 0.4 and $T=300 \mathrm{~K}$ the calculated coordination numbers are $\mathrm{Cs}^{\mathrm{nb}}(\mathrm{O})=9.2$ and $\mathrm{Cs}^{b}(\mathrm{O})=11.6$ for cutoff distances of 4.1 and $4.4 \AA$, respectively, from the particular Cs ion. For other compositions and temperatures the $\mathrm{Cs}^{\mathrm{nb}}$ or $\mathrm{Cs}^{b}$ population is not adequate to obtain statistically reliable results. The coordination numbers for $\mathrm{Cs}$ ions found in this work are considerably larger than those for $\mathrm{Li}$ ions, $\mathrm{Li}^{\mathrm{nb}}(\mathrm{O})=5.5$ and $\mathrm{Li}^{b}(\mathrm{O})=8,{ }^{29}$ and this is fully consistent with the size difference of $\mathrm{Cs}$ and $\mathrm{Li}$ ions. The average $\mathrm{Cs}(\mathrm{O})$ coordination number is about ten in very good agreement with results reported for crystalline $\mathrm{Cs}$ triborate. ${ }^{50}$

In the following, we examine whether the distinction of Cs ions into $\mathrm{Cs}^{b}$ and $\mathrm{Cs}^{\mathrm{nb}}$ types is reflected also in their vibrational properties. The vibrational density of states $\Phi(\omega)$ of metal ions in glass can be calculated from the Fourier transform of their velocity autocorrelation function $\Phi(t)$ obtained from the following expression:

$$
\Phi(t)=\left\langle\frac{1}{N} \sum_{j=1}^{N} \vec{v}_{j}(t) \vec{v}_{j}(0)\right\rangle,
$$

where $\vec{v}_{j}(t)$ is the velocity of metal ion $j$ at time $t$ and $N$ is the number of metal ions. ${ }^{21,29,46}$ We have applied this formalism to calculate separately the $\Phi(\omega)$ for $\mathrm{Cs}^{b}$ and $\mathrm{Cs}^{\mathrm{nb}}$ ions. The results for $x=0.4$ and $T=300 \mathrm{~K}$ are reported in Fig. 7(a) and are compared with the experimental far-infrared spectrum of the $x=0.33 \mathrm{Cs}$ borate glass. ${ }^{20}$ As shown, the $\Phi(\omega)$ responses for $\mathrm{Cs}^{b}$ and $\mathrm{Cs}^{\mathrm{nb}}$ ions are in the far-infrared region are quite broad. Nevertheless, they are clearly distinguished and the spectral weight attributed to $\mathrm{Cs}^{\mathrm{nb}}$ ions contributes mostly to the high-frequency part of the spectrum, whereas the response of $\mathrm{Cs}^{b}$ ions is active mainly at lower frequencies. This result strongly supports previous findings for the vibrational properties of lithium ions in borate glasses, ${ }^{29}$ in the sense that the distinction of metal ions according to the nature of 


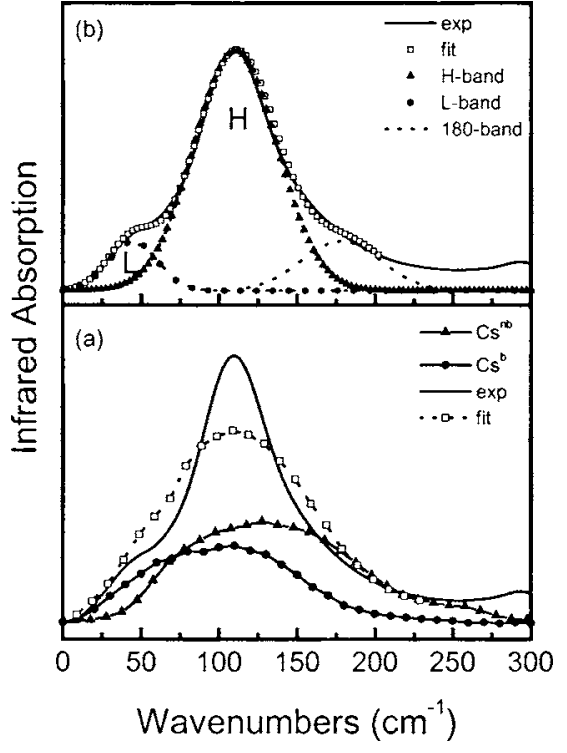

FIG. 7. (a) Calculated power spectra of Cs ions in bridging-type $\left(\mathrm{Cs}^{b}\right)$ and nonbridging-type $\left(\mathrm{Cs}^{\mathrm{nb}}\right)$ sites in the simulated $0.4 \mathrm{Cs}_{2} \mathrm{O}-0.6 \mathrm{~B}_{2} \mathrm{O}_{3}$ glass at $T$ $=300 \mathrm{~K}$. A linear combination of the power spectra is shown for comparison with the experimental far-infrared spectrum of the $0.33 \mathrm{Cs}_{2} \mathrm{O}-0.67 \mathrm{~B}_{2} \mathrm{O}_{3}$ glass. (b) The experimental far-infrared absorption profile shown in (a) is deconvoluted into Gaussian components (denoted by $L$ and $H$ ) originating from $\mathrm{Cs}-\mathrm{O}$ vibrations in different local environments. The third component band at ca. $180 \mathrm{~cm}^{-1}$ was attributed (Ref. 20) to libration modes of disconnected segments of the borate network.

their sites in glass is very well reflected also in their shorttime dynamics. In addition, these findings are in line with our earlier analysis of experimental far-infrared spectra into two component bands $[L$ and $H$ in Fig. 7(b)], and their assignment to the alkali ion site vibrations in at least two distributions of ion hosting sites. ${ }^{20,51}$ This work allows now a more detailed description of bands $H$ and $L$ in terms of the Cs-O vibrations in nb- and $b$-type sites, respectively.

\section{CONCLUSIONS}

In a continuation of our recent work on moleculardynamics (MD) simulations on Li borate glasses, ${ }^{27-29}$ this paper presents MD study of $x \mathrm{Cs}_{2} \mathrm{O}-(1-x) \mathrm{B}_{2} \mathrm{O}_{3}$ glasses as a function of composition $(0.2 \leqslant x \leqslant 0.4)$ and temperature $(T$ $=300,1250 \mathrm{~K})$. The main purpose of the present investigation is to provide insights on the role of alkali metal ions in aspects of structure and ion dynamics. The short-range-order (SRO) units building the Cs glass network were found to be borate tetrahedra $\left(\mathrm{B} \emptyset_{4}^{-}\right)$and triangles $\left(\mathrm{B} \emptyset_{3}, \mathrm{~B}_{2} \mathrm{O}^{-}\right.$, and

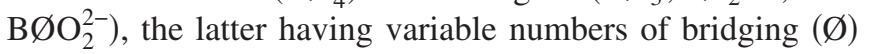
and nonbridging $\left(\mathrm{NBO}=\mathrm{O}^{-}\right)$oxygen atoms. From the analysis of the $\mathrm{B}-\mathrm{O}$ and the NBO-NBO radial distribution functions the molar fractions of the SRO units were calculated and found to depend strongly on both $\mathrm{Cs}_{2} \mathrm{O}$ content, $x$, and temperature. In particular, it was shown that the increase of $x$ leads to the progressive depolymerization of the glass network by increasing the relative abundance of NBOcontaining units at the expense of the $\mathrm{B} \emptyset_{4}^{-}$tetrahedra. This network transformation process was found to be enhanced at higher temperatures, and the extent of this effect is increased in glasses with larger alkali contents. Such structural changes were described in terms of isomerization [Eq. (6)] and disproportionation [Eq. (7)] equilibria between borate tetrahedra and triangles, and were associated with the increase of the fragile character of the glass with alkali content. Comparison of the present results with our previous study ${ }^{29}$ shows that at $x=0.2$ the $\mathrm{Cs}$ and $\mathrm{Li}$ glasses exhibit great similarities in the type and relative population of the SRO units. However, simulated glasses with larger alkali contents $(x=0.3,0.4)$ show a dependence on alkali ion, with Cs borates having a larger tendency for NBO-containing units than do Li borate glasses. In addition, the local $\mathrm{B}-\mathrm{NBO}$ and metal ion-oxygen bonding characteristics were found to vary with alkali ion. In particular, the average $\mathrm{B}-\mathrm{NBO}$ bond was found to be stronger in Cs glasses and the metal ion hosting sites to involve larger coordination numbers and longer metal ion-oxygen distances than those for lithium borates. Such effects were correlated naturally with the field strength and ion size differences of the two alkali ions.

The investigation of the microstructure of Cs ion sites reveals the existence of two types of environments that retain their identity during the simulation time; the first is formed exclusively by bridging oxygen atoms ( $b$ type) and the second by both bridging and nonbridging oxygens (nb type). Similarly, cations are distinguished as either $\mathrm{Cs}^{b}$ or $\mathrm{Cs}^{\mathrm{nb}}$ if they reside for more than $75 \%$ of the simulation time $(\sim 180 \mathrm{ps})$ in $b$-type or nb-type sites, respectively. This distinction is manifested also on the vibrational properties of Cs ions; i.e., the calculated $\mathrm{Cs}^{\mathrm{nb}}$ ion site vibrational response appears at higher far-infrared frequencies than does that of $\mathrm{Cs}^{b}$ ions. This result is compatible with our previous findings for Li borates ${ }^{29}$ and offers an explanation for the microscopic origin of the two component bands resolved previously in the experimental far-infrared spectra.

\section{ACKNOWLEDGMENT}

Partial support by the EU (Project No. HPMD-CT-200000033) is gratefully acknowledge.

${ }^{1}$ For a review article on early studies of borate glasses see: D. L. Griscom, Borate Glasses: Structure, Properties and Applications, edited by L. D. Pye, V. D. Frechette, and N. J. Kreidl (Plenum, New York, 1978), pp. 11-149.

${ }^{2}$ J. Krogh-Moe, Phys. Chem. Glasses 6, 46 (1965).

${ }^{3}$ A. H. Silver and P. J. Bray, J. Chem. Phys. 29, 984 (1958).

${ }^{4}$ P. J. Bray and J. G. O'Keefe, Phys. Chem. Glasses 4, 37 (1961).

${ }^{5}$ G. E. Jellison, S. A Feller, and P. J. Bray, Phys. Chem. Glasses 19, 52 (1978).

${ }^{6}$ W. L. Konijnendijk and J. M. Stevels, J. Non-Cryst. Solids 18, 307 (1975).

${ }^{7}$ R. L. Mozzi and B. E. Warren, J. Appl. Crystallogr. 3, 251 (1970).

${ }^{8}$ P. A. V. Johnson, A. C. Wright, and R. N. Sinclair, J. Non-Cryst. Solids 50, 281 (1982).

${ }^{9}$ P. C. Li, A. C. Ghose, and G. J. Su, J. Am. Ceram. Soc. 45, 83 (1962); 45, 89 (1962).

${ }^{10}$ B. D. McSwain, N. F. Borelli, and G. J. Su, Phys. Chem. Glasses 4, 1 (1963).

${ }^{11}$ A. J. Easteal and D. J. Udy, Phys. Chem. Glasses 14, 107 (1973).

${ }^{12}$ J. A. Duffy and M. D. Ingram, J. Non-Cryst. Solids 21, 273 (1976).

${ }^{13}$ K. K. Karsch, Glastech. Ber. 35, 234 (1962).

${ }^{14}$ J. E. Shelby, J. Am. Ceram. Soc. 66, 225 (1983).

${ }^{15}$ D. R. Uhlmann, A. G. Kolbeck, and D. L. DeWitte, J. Non-Cryst. Solids 5, 426 (1971).

${ }^{16}$ J. Zhong and P. J. Bray, J. Non-Cryst. Solids 111. 67 (1989).

${ }^{17}$ P. J. Bray, Proceedings of the Second International Conference on Borate 
Glasses, Crystals and Melts, edited by A. C. Wright, S. A. Feller, and A. C. Hannon (Society of Glass Technology, Sheffield, UK, 1997), pp. 1-20.

${ }^{18}$ G. D. Chryssikos, E. I. Kamitsos, and M. A. Karakassides, Phys. Chem. Glasses 31, 109 (1990).

${ }^{19}$ E. I. Kamitsos, G. D. Chryssikos, and M. A. Karakassides, Phys. Chem. Glasses 29, 121 (1988).

${ }^{20}$ E. I. Kamitsos, A. P. Patsis, and G. D. Chryssikos, J. Non-Cryst. Solids 152, 246 (1993).

${ }^{21}$ A. H. Verhoef and H. W. den Hartog, J. Non-Cryst. Solids 182, 235 (1995).

${ }^{22}$ A. N. Cormack and B. Park, Phys. Chem. Glasses 41. 272 (2000).

${ }^{23}$ R. E. Youngman and J. W. Zwanziger, J. Am. Chem. Soc. 117, 1397 (1995).

${ }^{24}$ O. Majerus, L. Cormier, G. Calas, and B. Beneu, Phys. Rev. B 67, 024210 (2003).

${ }^{25}$ J. R Berryman, S. A. Feller, M. Affatigato, M. Kodama, B. M. Meyer, S. W. Martin, F. Borsa, and S. Kroeker, J. Non-Cryst. Solids 293, 483 (2001).

${ }^{26}$ M. Kodama and S. Kojima, Proceedings of the Second International Conference on Borate Glasses, Crystals and Melts, edited by A. C. Wright, S. A. Feller, and A. C. Hannon (Society of Glass Technology, Sheffield, UK, 1997), pp. 181-188.

${ }^{27}$ W. Clarida, J. R. Berryman, M. Affatigato, S. A. Feller, S. Kroeker, J. Ash, J. W. Zwanziger, B. Meyer, F. Borsa, and S. W. Martin, Phys Chem. Glasses 44, 215 (2003).

${ }^{28}$ C. P. E. Varsamis, A. Vegiri, and E. I. Kamitsos, Condens. Matter Phys. 4, 119 (2001).

${ }^{29}$ C. P. E. Varsamis, A. Vegiri, and E. I. Kamitsos, Phys. Rev. B 65, 104203 (2002).

${ }^{30}$ C. P. E. Varsamis, A. Vegiri, and E. I. Kamitsos, J. Non-Cryst. Solids 307-310, 956 (2002).

${ }^{31}$ M. Royle, J. MacKenzie, J. Taylor, M. Sharma, and S. Feller, J. NonCryst. Solids 177, 242 (1994).
${ }^{32}$ O. V. Mazurin and M. V. Streltsina, Handbook of Glass Data (Elsevier, New York, 1985), Pt. B.

${ }^{33}$ H. C. Lim and S. Feller, J. Non-Cryst. Solids 94, 36 (1987).

${ }^{34}$ M. P. Allen and D. J. Tildesley, Computer Simulations of Liquids (Clarendon, Oxford, 1986), p.156.

${ }^{35}$ T. F. Soules, J. Non-Cryst. Solids 49, 29 (1982).

${ }^{36}$ R. J. Araujo, J. Non-Cryst. Solids 58, 201 (1983).

${ }^{37}$ J. F. Stebbins and S. E. Ellsworth, J. Am. Ceram. Soc. 79, 2247 (1996);S. Sen, Z. Xu, and J. F. Stebbins, J. Non-Cryst. Solids 226, 29 (1998).

${ }^{38}$ C. P. Varsamis, E. I. Kamitsos, and G. D. Chryssikos, Phys. Rev. B 60, 3885 (1999).

${ }^{39}$ G. Herms and J. Sakowski, Phys. Chem. Glasses 41, 309 (2000).

${ }^{40} \mathrm{R}$ Akagi, N. Ohtori, and N. Umesaki, J. Non-Cryst. Solids 293-295, 471 (2001).

${ }^{41}$ J. K Maranas, Y. Chen, D. K. Stillinger, and F. H. Stillinger, J. Chem. Phys. 115, 6578 (2001).

${ }^{42}$ C. A Angell, J. Non-Cryst. Solids 131-133, 13 (1991), and references therein.

${ }^{43}$ G. D. Chryssikos, J. A. Duffy, J. K. Hutchinson, M. D. Ingram, E. I. Kamitsos, and A. Pappin, J. Non-Cryst. Solids 172-174, 378 (1994).

${ }^{44}$ S. V. Nemilov, Glass Phys. Chem. 23, 1 (1997).

${ }^{45}$ G. N. Greaves and K. L. Ngai, Phys. Rev. B 52, 6358 (1995).

${ }^{46}$ A. Karthikeyan and K. J. Rao, J. Phys. Chem. B 101, 3105 (1997).

${ }^{47}$ Y. D. Yiannopoulos, G. D. Chryssikos, and E. I. Kamitsos, Phys. Chem. Glasses 42, 164 (2001).

${ }^{48}$ E. I. Kamitsos, G. D. Chryssikos, and M. A. Karakassides, Phys. Chem. Glasses 30, 229 (1989).

${ }^{49}$ E. I. Kamitsos, M. A. Karakassides, A. P. Patsis, and G. D. Chryssikos, J. Non-Cryst. Solids 116, 115 (1990).

${ }^{50}$ J. Krogh-Moe, Acta Crystallogr., Sect. B: Struct. Crystallogr. Cryst. Chem. 30, 1178 (1974).

${ }^{51}$ E. I Kamitsos and G. D. Chryssikos, Solid State Ionics 105, 75 (1998). 